NASA/TM-2002-211287

\title{
Entropically Driven Self-Assembly of Colloidal Crystals on Templates in Space
}

\author{
Arjun G. Yodh \\ Gregory A. Zimmerli \\ Glenn Research Center, Cleveland, Ohio
}

University of Pennsylvania, Philadelphia, Pennsylvania 
Since its founding, NASA has been dedicated to the advancement of aeronautics and space science. The NASA Scientific and Technical Information (STI) Program Office plays a key part in helping NASA maintain this important role.

The NASA STI Program Office is operated by Langley Research Center, the Lead Center for NASA's scientific and technical information. The NASA STI Program Office provides access to the NASA STI Database, the largest collection of aeronautical and space science STI in the world. The Program Office is also NASA's institutional mechanism for disseminating the results of its research and development activities. These results are published by NASA in the NASA STI Report Series, which includes the following report types:

- $\quad$ TECHNICAL PUBLICATION. Reports of completed research or a major significant phase of research that present the results of NASA programs and include extensive data or theoretical analysis. Includes compilations of significant scientific and technical data and information deemed to be of continuing reference value. NASA's counterpart of peerreviewed formal professional papers but has less stringent limitations on manuscript length and extent of graphic presentations.

- TECHNICAL MEMORANDUM. Scientific and technical findings that are preliminary or of specialized interest, e.g., quick release reports, working papers, and bibliographies that contain minimal annotation. Does not contain extensive analysis.

- CONTRACTOR REPORT. Scientific and technical findings by NASA-sponsored contractors and grantees.
- CONFERENCE PUBLICATION. Collected papers from scientific and technical conferences, symposia, seminars, or other meetings sponsored or cosponsored by NASA.

- SPECIAL PUBLICATION. Scientific, technical, or historical information from NASA programs, projects, and missions, often concerned with subjects having substantial public interest.

- TECHNICAL TRANSLATION. Englishlanguage translations of foreign scientific and technical material pertinent to NASA's mission.

Specialized services that complement the STI Program Office's diverse offerings include creating custom thesauri, building customized data bases, organizing and publishing research results ... even providing videos.

For more information about the NASA STI Program Office, see the following:

- Access the NASA STI Program Home Page at http://www.sti.nasa.gov

- E-mail your question via the Internet to help@sti.nasa.gov

- Fax your question to the NASA Access Help Desk at 301-621-0134

- Telephone the NASA Access Help Desk at 301-621-0390

- Write to:

NASA Access Help Desk

NASA Center for AeroSpace Information 7121 Standard Drive

Hanover, MD 21076 
NASA/TM-2002-211287

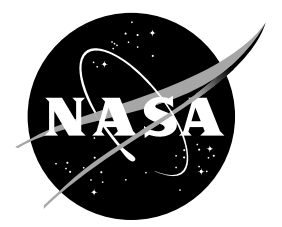

\title{
Entropically Driven Self-Assembly of Colloidal Crystals on Templates in Space
}

\author{
Arjun G. Yodh \\ University of Pennsylvania, Philadelphia, Pennsylvania \\ Gregory A. Zimmerli \\ Glenn Research Center, Cleveland, Ohio
}

Prepared for the

International Space Station Utilization-2001

sponsored by the American Institute of Aeronautics and Astronautics

Cape Canaveral, Florida, October 15-18, 2001

National Aeronautics and

Space Administration

Glenn Research Center 
Available from

NASA Center for Aerospace Information 7121 Standard Drive

National Technical Information Service 5285 Port Royal Road Hanover, MD 21076 


\title{
ENTROPICALLY DRIVEN SELF-ASSEMBLY OF COLLOIDAL CRYSTALS ON TEMPLATES IN SPACE
}

\author{
Arjun G. Yodh \\ University of Pennsylvania \\ Philadelphia, Pennsylvania \\ Greg Zimmerli \\ National Aeronautics and Space Administration \\ Glenn Research Center \\ Cleveland, Ohio
}

\begin{abstract}
These experiments aim to create new colloidal crystalline materials, to study the assembly and thermodynamics of these materials, to measure the optical properties of these materials, and to fix the resulting structures so that they can be brought back and studied on earth. In microgravity, the elimination of particle sedimentation effects creates a purely "thermodynamic" environment for colloidal suspensions wherein particle size, volume fraction, and interparticle interactions are the primary determinants of the assembled structures. We will control the colloidal assembly process using attractive, entropic particle interactions brought about by the depletion effect. By using attractive interactions for colloidal assembly we create conditions for growth that resemble those associated with "conventional" microscopic systems such as atoms and molecules. This approach differs qualitatively from the more common "spacefilling" mode of colloidal crystal growth that is driven purely by packing constraints. It is anticipated that at least some of the solidified structures will survive reentry to earth's gravitational field, and that their optical, magnetic, and electrical properties can then be studied in detail upon return.
\end{abstract}

\section{BRIEF OVERVIEW OF SCIENTIFIC TOPIC AND BRIEF LITERATURE SURVEY}

The conceptual motivations for this work are coupled to current research in complex fluids, optics, and many-body statistical physics. The bulk of our research however, centers on the physics of complex fluids, an emerging subfield of condensed matter physics. Complex fluids are soft materials such as colloidal suspensions, emulsions, polymer solutions, membranes, and mixtures thereof, whose structure and dynamics are strongly influenced by entropy and by relatively weak mechanical forces. In this proposal we focus on mixtures of colloidal particles and other soft materials. These materials are intriguing from both fundamental and practical points of view.

Colloidal suspensions exhibit a wide range of structures, both ordered and disordered, with correlations that often extend to the size of the system. Furthermore they exhibit a wide range of dynamics, which can often be tied closely to the structure of the system. Their rich phenomenology derives from a fascinating interplay of physical, chemical and hydrodynamic mechanisms whose realization provides a unique opportunity for the study of statistical mechanics in classical many-body systems. Recent experimental and theoretical progress relevant to the present proposal includes studies of the role of entropy and interparticle interaction in affecting self-assembly ${ }^{1}$ and directed assembly in systems of monodisperse hard-spheres, ${ }^{2-12}$ particle suspensions with added particles or polymers, ${ }^{13-52}$ monodisperse emulsions with added polymer, ${ }^{41,43}$ binary emulsions, ${ }^{38}$ suspensions of rod-like particles in mixtures of spheres, ${ }^{53-60}$ liquid crystal emulsions, ${ }^{61-63}$ and charged-stabilized particle suspensions. ${ }^{64-71}$

Research on these substances is also driven by a variety of practical applications (see for example [72] and references therein) ranging from the prospect of using these materials as templates for photonic materials ${ }^{73-75}$ and lithography, ${ }^{76,77}$ to their uses in ceramics and as biochemical sensors. ${ }^{78,79}$ In a different vein, studies of complex fluids are increasingly stimulated by analogies from cell biology, ${ }^{80,81}$ and in some cases provide critical insights about mechanisms that arise in the crowded, aqueous, and near-roomtemperature cellular environments. In still other 
systems, particle additives offer practical control of fluid rheologies, thus improving the performances of conventional materials such as paints, motor oils, food and cosmetics.

\section{DEPLETION PHENOMENOLOGY}

The entropically driven low-volume fraction systems we will study are reasonably well approximated as a suspended mixture of hard-spheres. Hard-sphere colloids lack attractive and long-range interactions, which typically compete with entropic effects to produce ordered phases. Nonetheless, as Asakura and Oosawa first noted, ${ }^{82}$ in mixtures of different size spherical particles an ordered arrangement of large spheres can increase the total entropy of the system by increasing the entropy of the small spheres. This phenomenon is depicted in Figure. 1. Because the center of mass of the small sphere cannot penetrate within $a_{S} / 2$ of the large sphere surface, a region of "excluded volume" surrounds each large sphere (here, $\mathrm{a}_{\mathrm{S}}\left(\mathrm{a}_{\mathrm{L}}\right)=$ small- (large-) sphere diameter). When the surfaces of the two large spheres approach within a small-sphere diameter, these excluded volume regions overlap one another, and the total volume accessible to the center of mass of the small spheres increases. The resulting increase in small sphere entropy thus induces the so-called attractive "depletion" force between the large spheres. At low concentrations of small spheres, simple models ${ }^{82-84}$ predict this energy of attraction is proportional to the volume fraction of the small spheres

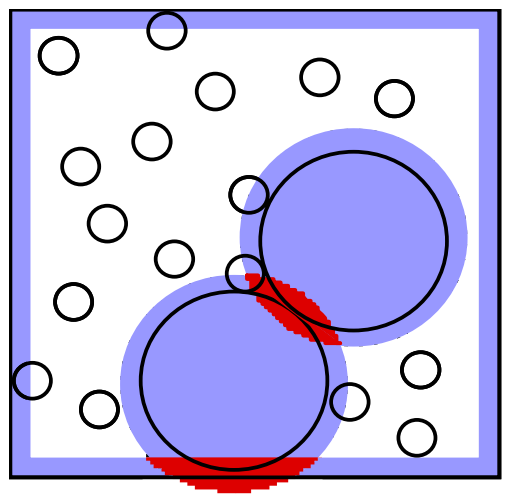

Figure 1. Illustration of the entropic interactions of hard sphere particles among themselves and with the wall. The small sphere centers of mass are excluded from the shaded blue regions. The red regions correspond to the overlap of excluded volumes, and thus represent the gain in volume near the surface is larger than that between two particles in the bulk. Note if figure is not colored, then blue = light grey and red $=$ dark grey.
$\left(\Phi_{\mathrm{S}}\right)$, and to the ratio of large- $\left(\mathrm{a}_{\mathrm{L}}\right)$ and small-sphere $\left(a_{S}\right)$ diameters. We have directly measured the form of this interaction potential as brought about by added particles, ${ }^{13}$ polymers ${ }^{14,85}$ and rods. ${ }^{86}$ In Figure 2 the measured large sphere potential of mean force is presented along with theoretical fits using the simple AO model; the AO model works very well at low small sphere concentration.

The attraction energy at contact is $\sim(3 / 2)\left(\mathrm{a}_{\mathrm{L}} / \mathrm{a}_{\mathrm{S}}\right) \Phi_{\mathrm{S}} \mathrm{k}_{\mathrm{B}} \mathrm{T}$, where $\mathrm{k}_{\mathrm{B}}$ is the Boltzmann constant and $\mathrm{T}$ the ambient temperature. This attraction energy can be several $\mathrm{k}_{\mathrm{B}} \mathrm{T}$ in practice. It has been observed to drive phase separation in monodisperse colloids with added polymer ${ }^{23,24,40,51,52}$ in monodisperse emulsions with added polymer, ${ }^{41,43}$ in binary emulsions, ${ }^{38}$ and in suspensions of silica and polystyrene spheres. ${ }^{18,19,87,88}$

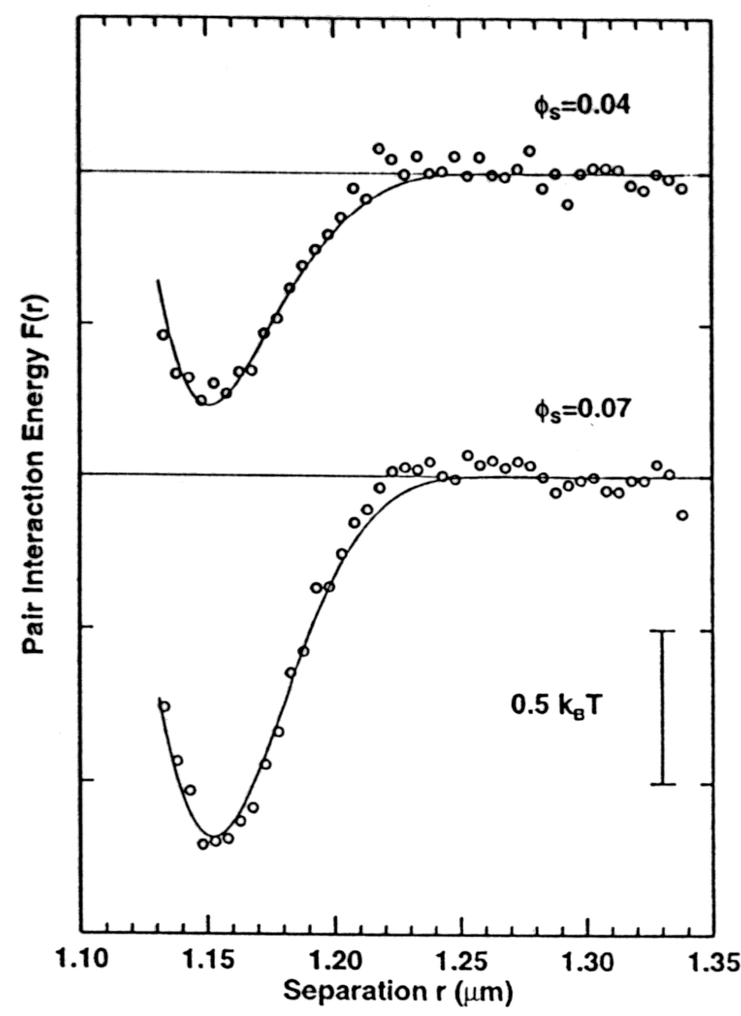

Figure 2. Entropic interaction potentials measured with small sphere volume fractions of $\Phi_{\mathbf{S}}=\mathbf{0 . 0 4}$ and $\Phi_{\mathrm{S}}=\mathbf{0 . 0 7}$ with the background potential $\left(\Phi_{S}=0\right)$ subtracted. The upturn on the leftmost end of the curves is due to the resolution broadened bare repulsion of the two spheres. The curves are fits to the Asakura-Oosawa model, blurred with a Gaussian kernel to account for our instrumental resolution. The large particles were $\sim 1.1 \mu \mathrm{m}$ diameter PMMA spheres, and the small particles were $\sim 83 \mathrm{~nm}$ PS spheres. 

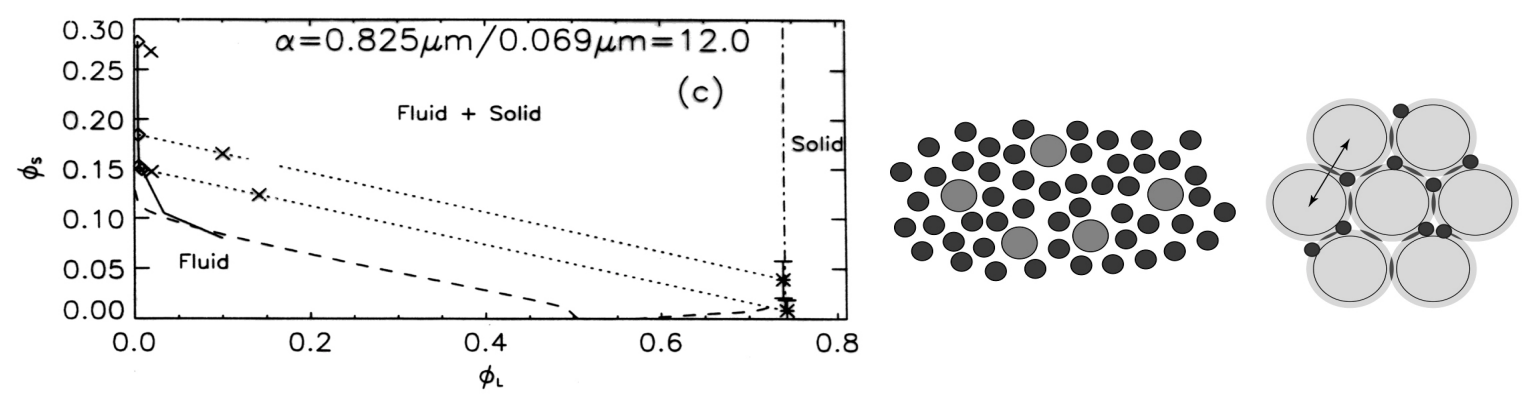

Figure 3. Left: Experimental phase diagram (solid line and points) and theory (dashed line) for the binary hard-sphere colloid. Cartoon of the fluid phase (center) and the solid phase (right) modeled by our theory.
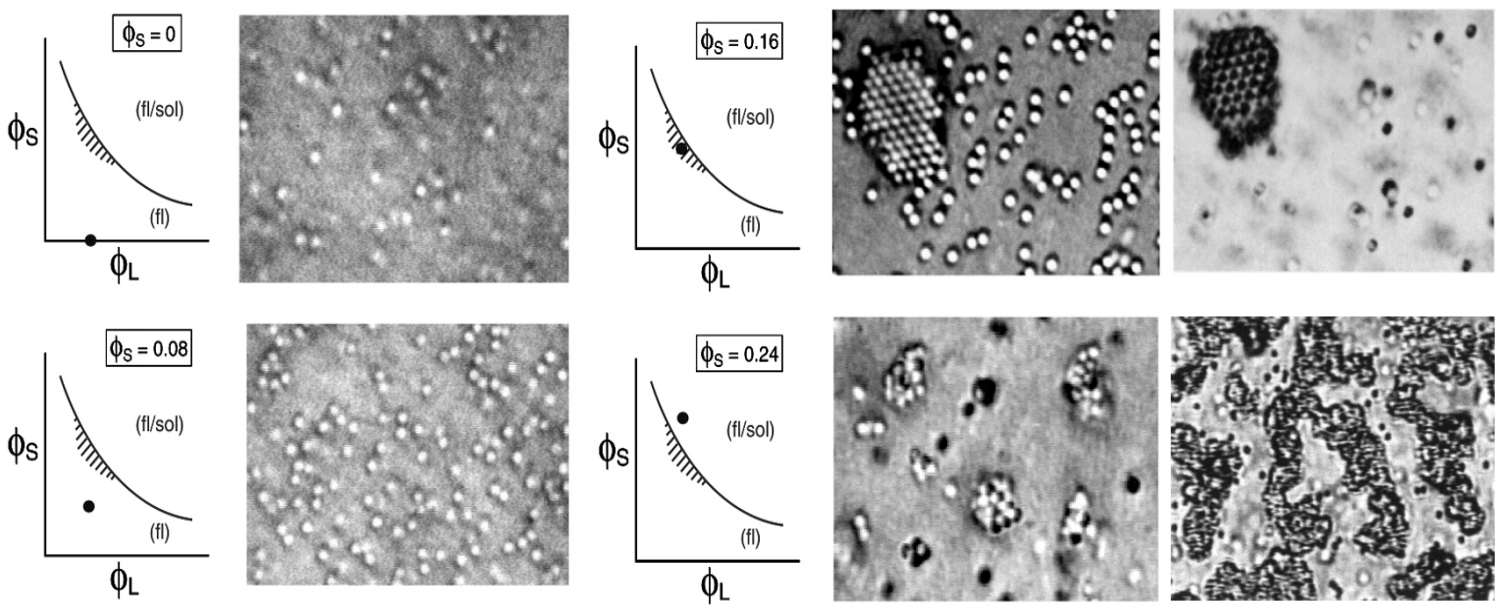

Figure 4. Microscope images of $0.825 \mu \mathrm{m} / 0.069 \mu \mathrm{m}$ binary particle suspensions as a function of small ball volume fraction $\Phi_{s}$. The large ball volume fraction is held constant at $\Phi_{L}=0.02$, and only the large balls are apparent in the images. To the left of each photo we show the sample preparation volume fractions (dot) along with the liquidus line. Most (Top, Bottom-left) of the images are taken just below the cell wall, and (Bottom-right) is imaged $\sim 20 \mu \mathrm{m}$ into the bulk sample. (See text for further discussion.)

In pure particle suspensions, for example mixtures of large and very small colloidal spheres, most experimental and theoretical evidence indicates that first order fluid-solid phase transitions occur in the bulk suspension. ${ }^{17-19,23,34,36,87-89}$ Experiments have determined transition volume fractions in a few samples with differing particle type, size, and size ratio. In Figure 3, we show a phase diagram along with some data ${ }^{18}$ produced by samples composed of $\sim 800 \mathrm{~nm}$-diameter polystyrene spheres and $\sim 70 \mathrm{~nm}$-diameter polystyrene spheres. At small total volume fraction the suspension is a fluid consisting of a mixture of different size hard spheres, but when the small sphere volume fraction is increased sufficiently, the mixture phase separates into a large-ball-poor hard-sphere fluid and a large-ball-rich colloidal crystal. The dotted lines are tie lines. The dashed lines are predictions of a simple theory ${ }^{18}$ which treated the fluid phase as a mixture of large and small hard spheres (see Fig. 3-center), deriving the pressure of the fluid from the Carnahan-Starling equation of state, ${ }^{90}$ and treated the solid phase as an FCC crystal of large spheres permeated by a fluid of small hardspheres. The driving force for crystallization is made apparent in Figure 3-right; when the lattice constant of the FCC crystal decreases, the regions of excluded volume overlap more, and thus create more entropy for the fluid of small spheres.

While carrying out these systematic experiments on binary colloidal suspensions, we discovered ${ }^{19}$ that the first instability arising in many binary particle mixtures was phase separation into an ordered surface phase and a disordered bulk liquid phase. Disordered and ordered surface phases can also be understood using simple excluded-volume entropy arguments, in this case between the large particle and the wall (depicted in Fig. 1). The entropic force on a particle near the wall surface is roughly twice as large as that between two large particles in the bulk!

In Figure 4 we illustrate the general systematics of these effects. These samples were composed of $\sim 0.8 \mu \mathrm{m}$ diameter large- and $\sim 0.07 \mu \mathrm{m}$ diameter smallpolystyrene-spheres suspended in water. The system 
was salted at a concentration of $\sim 0.01 \mathrm{M}$ so that the particle interactions were approximately hard-sphere. The water was a mixture of $\mathrm{D}_{2} \mathrm{O}$ and $\mathrm{H}_{2} \mathrm{O}$ in order to create near neutral buoyancy conditions for polystyrene. The large ball volume fraction was fixed at $\Phi_{\mathrm{L}}=0.02$, and the small sphere volume fraction was varied. We designed a small glass sample cell $(\sim 100 \mu \mathrm{m}$ thick) so that the large particles in these suspensions could be observed in real time using our optical microscope. To the left of each photograph is a "quasi-phase-diagram" that indicates the volumefraction of the large and small spheres, as well as our estimated liquidus line.

In Figure 4 (top-left, right; bottom-left) the focal plane was chosen just beneath the sample cell wall in order to reveal surface dynamics, and in Figure 4 (bottom-right) we have chosen a slice within the cell in order to reveal the bulk dynamics. We see that the large particle concentration increases on the wall surface with increasing small sphere volume fraction, and that surface crystallization begins in a region of the phase diagram just below the liquidus line (note, the lifetime of the large particles on the wall also increases dramatically $\left(>>10^{3}\right)$ between (a) and (b)).

The crystalline structure grows rapidly along the wall, and more slowly into the bulk. In Figure 4 (topright) we show an image (rightmost) of the second layer of the surface crystal; notice, the number density of large particles in the background fluid is much less than on the surface. For samples prepared with volume fractions above the liquidus line (Fig. 4 (bottom-right)), a rapid nucleation of large ball clusters is revealed (in less than $10 \mathrm{~min}$ ). These clusters typically sediment or combine to form a gel (rightmost image of Fig. 4 (bottom-right)). Thus there exist interesting windows of opportunity in these low-volume-fraction entropically driven systems wherein high quality particle assembly is possible, free of bulk complications. We have grown surface crystals as large as $1 \mathrm{~mm}$; the surface crystals grow laterally much more quickly than into the bulk.

In closing out this section we briefly describe some fundamental colloid science that bear directly on entropic effects described above. One important parameter in this problem is the particle diameter ratio $\alpha=\mathrm{a}_{\mathrm{L}} / \mathrm{a}_{\mathrm{S}}$. When $\alpha$ is small $(\sim 1$ to 1.7$)$ a variety of crystal structures such as $\mathrm{AB}_{13}$ and $\mathrm{AB}_{2}$ have been observed $^{30,45,91,92}$ and have been predicted theoretically ${ }^{93-95}$ at high volume fraction $(\sim 0.5)$. In this regime the structures are largely determined by packing geometry and are strongly $\alpha$-dependent. Microgravity experiments on some of these systems are planned under the supervision of Weitz and Pusey. When $\alpha$ exceeds 6 , as in most of the experiments performed in our laboratory, the small particles diffuse freely through the interstices of the large particle crystals, and transitions occur at much lower total volume fraction.
Another important parameter is the "softness" of the effective large particle interactions. This becomes an issue, for example, if the small particle is replaced by a polymer. When the polymer depletants are relatively large, the phase diagram for the suspension changes dramatically_gas phases, liquid phases and solid phases are all possible, gas-liquid coexistence occurs in addition to liquid-solid coexistence, and the suspension has a critical point. ${ }^{51,84}$ Finally, there is always an issue of particle polydispersity. This has been investigated recently in the context of monodisperse colloids. ${ }^{96-98}$ In essence the particle polydispersity makes the colloidal crystals more glass-like, so that the free energy differences between crystalline and liquid or glass structures are reduced. Phase transitions are still observed however, with polydispersities as large as 10 percent in the monodisperse systems, but the transitions are shifted to higher volume fractions. All of the issues described in this paragraph (and more) are of current interest and debate in the colloid science community.

\section{CONTROLLED COLLOIDAL EPITAXY USING ENTROPY AND SURFACE TEMPLATES}

The entropic excluded volume effects induce attractions between particles and even stronger attractions between particles and walls. Can similar effects be used to position particles on substrates or move them in a predetermined way? The answer is yes. Geometric features on a surface can create entropic force fields that trap, repel, or induce drift of the larger particles in suspension. ${ }^{15}$ Large particles, moving in the vicinity of steps, grooves, or corners cut into a flat substrate, modify the small-sphere free volume in a manner dependent on large particle position and on the size and shape of the geometric features (see Fig. 5 for schematic examples). We have identified and quantified these phenomena at step edges, ${ }^{15}$ near corners, ${ }^{99}$ and in vesicles. $^{16}$

Recently, we have extended the entropic schemes further to facilitate growth of three-dimensional structures. ${ }^{100}$ The new paradigm is well suited for microgravity. Our method is an equilibrium approach that combines thermodynamics and geometry. Specifically, we have combined entropic depletion attractions and templated surfaces with spatially periodic 1-dimensional (1D) and 2-dimensional (2D) height profiles to create a periodic surface potential, and then to drive the growth of two- and threedimensional particle structures nucleating from these templates. We used the entropic phenomenon to attract and repel colloidal spheres from specific positions on a corrugated template formed by imprinting ${ }^{101,102}$ an optical grating. We have observed $1 \mathrm{D}, 2 \mathrm{D}$ and $3 \mathrm{D}$ commensurate structures that form as a function of 


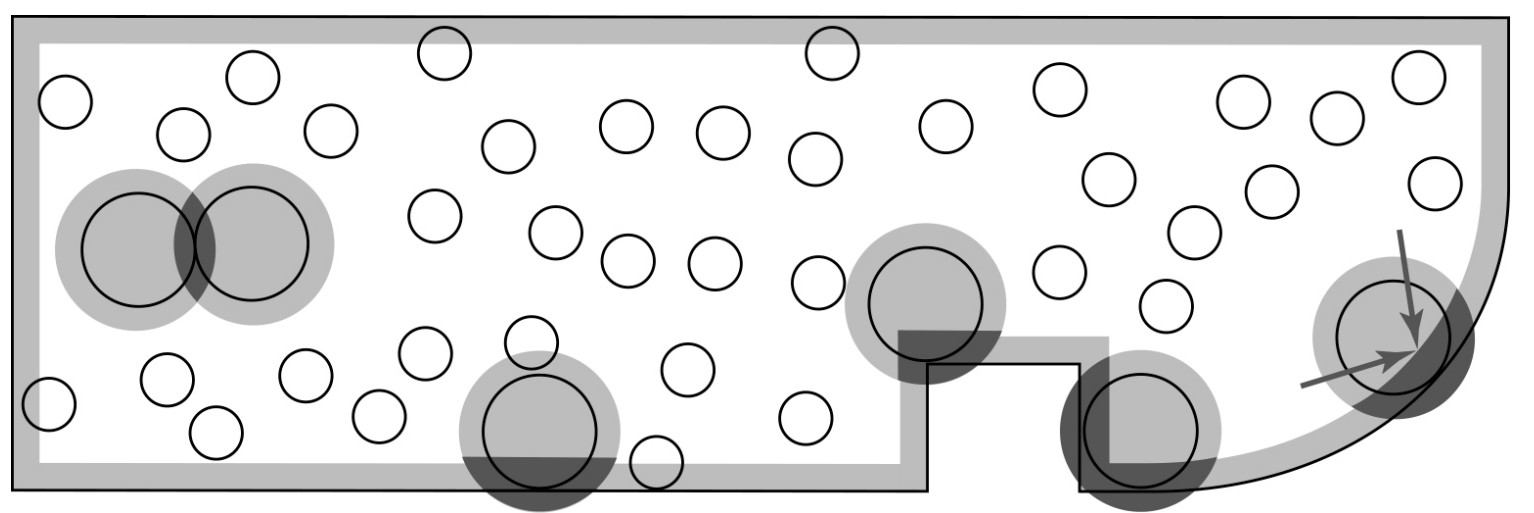

Figure 5: Schematic of depletion effect in various geometries. Dark shaded region represents the gain of small sphere excluded volume (entropy).
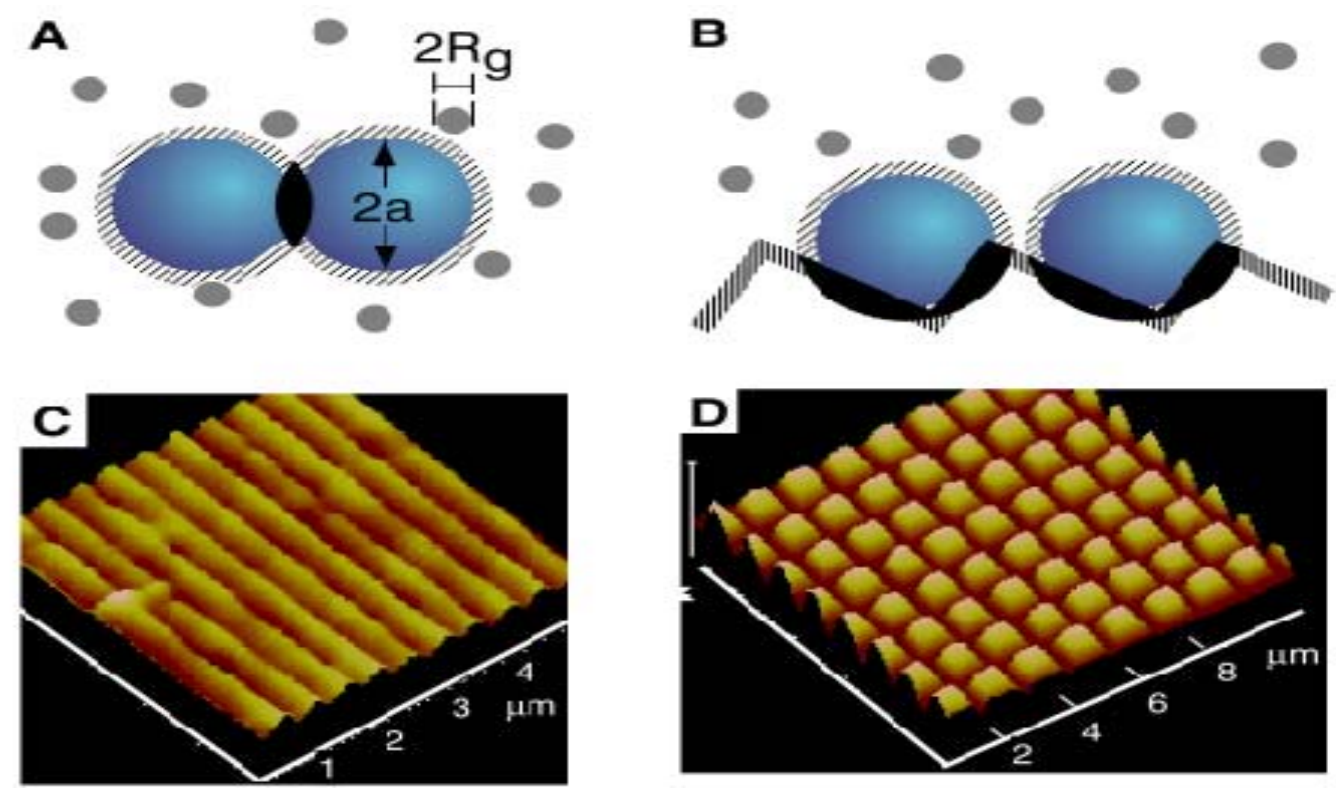

Figure 6. AFM images of grating templates. (A) Depletion effect in bulk suspension. (B) Depletion effect in grooves of a grating template. (C) AFM image of 1-dimensional grating template. (D) AFM image of 2-dimensional template made by crossing the grating (see text).

sphere size and grating periodicity. ${ }^{100}$ The $2 \mathrm{D}$ surface potential induced both liquid- and solid-like surface structures, and it provided the optimum template for growth of a large, defect-free FCC crystal.

Our basic ideas and some results are shown in Figures 6 and 7. In Figures 6(a) and (b) we revisit the depletion force mechanism. The main new point is that spheres in contact with the two (four) flat walls of the grating groove (Fig. 6(b)) experience an attractive force up to four (eight) times the two-sphere value in the bulk suspension, and are thus driven forced to the grating valleys. ${ }^{15,99}$ Thus the ordered template creates a periodic surface potential for the colloidal spheres.

Imprint or stamping techniques provide a simple way to make replicas of surface structures. ${ }^{101,102} \mathrm{We}$ have developed a simple imprint technique that employs an optical diffraction grating to create a geometrical template. In Figures 6(c) and (d) we show an Atomic Force Microscope (AFM) image of a replica optical grating in a PMMA film. We first spin coat a $\sim 400 \mathrm{~nm}$ thick layer of PMMA on a glass substrate. Pressing a diffraction grating onto the PMMA film above its glass temperature $\left(\sim 120^{\circ} \mathrm{C}\right)$ creates a replica in the film (Fig. 6(c)). ${ }^{101}$ By rotating the substrate $90^{\circ}$ and imprinting a second time, we create twodimensional periodic structures, resembling an array of square pyramids (Fig. 6(d)). The templates form one wall of the sealed sample-chambers, which, in our case were 30 to $100 \mu \mathrm{m}$ thick and contain a few microliters of sample.

In Figure 7 we show some of our results with the 2D grating template. In this case the colloid samples consisted of 0.7 to $1.2 \mu \mathrm{m}$ diameter PMMA (polymethylmethacrylate) spheres stabilized by a 
grafted layer of poly-12-hydroxy stearic acid..$^{27,103}$ In an organic solvent mixture of decalin/cyclohexylbromide, these spheres are nearly density matched with a refractive index mismatch of $<0.01$. Such small index mismatches reduce light scattering, facilitating optical microscopy deep into the suspension. Depletion attractions were induced by adding polystyrene polymer, with a radius of gyration, $\mathrm{R}_{\mathrm{g}} \sim 15 \mathrm{~nm}$ $\left(\mathrm{M}_{\mathrm{w}}=320,000, \mathrm{M}_{\mathrm{w}} / \mathrm{M}_{\mathrm{n}}=1.04\right.$, Polymer Laboratories $)$. We scaled the concentration of polymer used with different sized spheres to keep the free energy reduction at contact, $\mathrm{F}_{0}$, fairly constant.

In our experiments we vary the spatial period $p$ of the template and the particle size. A variety of $2 \mathrm{D}$ surface structures form within an hour and then evolve slowly thereafter. The results are summarized in Figure 7 as a function of the ratio of the mean interparticle spacing, $d$ (which was usually somewhat larger than the particle diameter), to the grating period.
When $\mathrm{d}$ is commensurate with the grating period at the ratios, 0.707 and 1.414, large crystal domains with fewer defects form. When the ratio is unity (i.e., we use a crossed grating commensurate with the FCC (100) plane) an FCC crystal was grown without stacking defects. A confocal microscope image of 20-layers of particles within the interior of a larger ( $>30$-layer) colloidal crystal is shown in Figure 7(d). Also shown in Figure 8 (along with the raw confocal image) is a reconstruction of the crystal based on particle centroiding.

The combination of depletion attraction and simple templating provides a qualitatively new route for controlled colloidal self-assembly of high quality colloidal crystals. Since the scheme employs an equilibrium process, it will work with any kind of 'nearly-hard-sphere' particle under appropriate suspension conditions. Thus it can be applied to a broader range of particles in microgravity, particles that
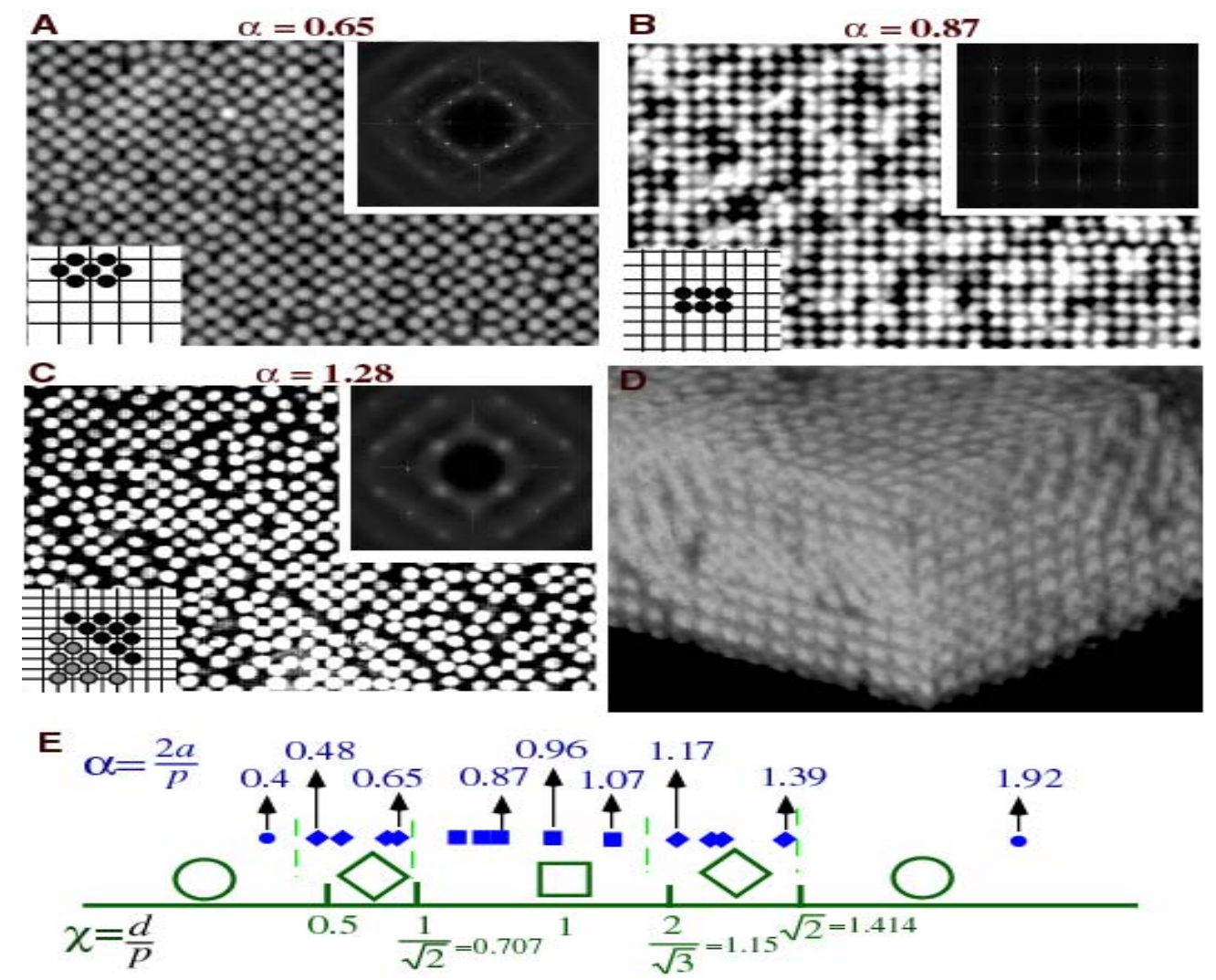

Figure 7. Assembly of cross-grating templates. For all data the volume fraction of the PMMA particles is 0.25 , and the concentration of polystyrene polymer is $0.1 \mathrm{mg} / \mathrm{ml}$. In $(E)$ we show the sequence of two-dimensional structures that nucleate on the grating template at particular ratios of the mean interparticle spacing, $d$, to the grating spatial period, $p$. (Note that the mean interparticle spacing is always at least $10 \%$ larger than the particle diameter, 2a). The structures in $(\mathrm{A}),(\mathrm{B})$, and $(\mathrm{C})$ are commensurate with the template, for $\chi$ close to and smaller than $0.707,1$, and 1.414 respectively. (D) is a 3D confocal image showing 20 layers of a FCC crystal grown on a template with $\chi=1$. 

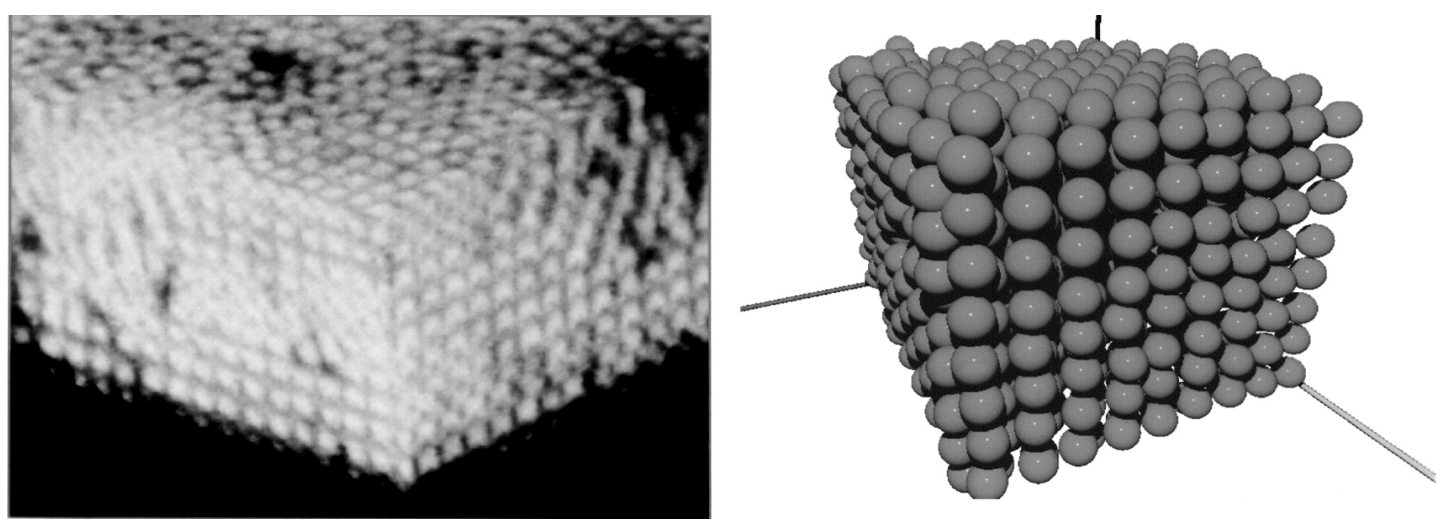

Figure 8. Reconstructed particle lattice based on centroiding of confocal images. Left: 3D confocal image showing 20 layers within the interior of a $>30$ layer fcc colloidal crystal grown on $d / p=1$ crossed-grating entropic template. Right: Computer reconstruction of the lattice based on the particle coordinates determined from the microscope images.

would not normally assemble thermodynamically due to sedimentation effects. Our grating imprint technique also provides a robust, rapid, and inexpensive templating methodology. In addition to the PMMA system described above, we have had some success assembling multilayer crystals of polystyrene and silica in aqueous suspensions. We have also had some very recent success nucleating and growing more open crystal structures such as BCC "hard-sphere" crystals with the PMMA system; this is optimized using a grating template with slightly different valley separations (compared to FCC).

\section{NEAR-PERFECT COLLOIDAL CRYSTALS}

In sections 2 and 3 we described entropic forces and entropically driven phase transitions, and we saw that the phenomena could be used in a very general way to grow high quality colloidal crystals. In this section we provide a very brief discussion about why high quality colloidal crystals are attractive.

Perhaps the most practical reason for the resurgence of interest in colloidal crystallization is that it is difficult to create patterned nano- and microscale materials that are ordered in three-dimensions. Modern lithographic techniques can have nanometer resolution and they often have exquisite versatility, but they are generally limited to defining features at surfaces and interfaces; thus, with few exceptions ${ }^{104-106}$ lithographic fabrication in three-dimensions remains a challenge. Laser holographic writing has recently been demonstrated in three dimensions, ${ }^{107}$ but this method also has limitations with respect to host material type and spatial resolution. An alternative route for creation of three-dimensional patterned materials is through selfassembly. Micron and submicron colloidal particles can assemble spontaneously into a wide range of highly ordered phases employing a wide variety of particle species. Such crystals can form spontaneously in thermal equilibrium, ${ }^{1,5,108,109}$ or through a variety of nonequilibrium schemes. For example, particle ordering may be facilitated by gravity, ${ }^{110}$ convection, ${ }^{11-116}$ electrohydrodynamic forces, ${ }^{117-119}$ chemical forces, ${ }^{120,121}$ or injection. ${ }^{122,123}$ The ordered arrays of particles have numerous potentially useful attributes.

When sufficiently ordered they often have novel optical properties. $^{73,75,124-127}$ For example, they can be used to alter the local photon density of states or to redirect light beams via diffraction. Such optical property control can lead to new classes of optical filters, switches and masks, ${ }^{128-134}$ or to host materials, which act as directional reflectors for embedded waveguides or light sources. ${ }^{135-141}$ In a related vein the ordered structures may eventually be employed as ultralow emissivity materials, or as novel linear and nonlinear optical based sensors. ${ }^{1,72,104,142-155}$

Particle arrays can also be used indirectly, as templates to create novel macroporous materials. Besides the use of the resulting inverse structures in photonics, ${ }^{77,156-164}$ precision macroporous materials have a wide range of potential chemical applications. For example, macroporous polymers have been used as catalytic surfaces and supports, ${ }^{165,166}$ separation and adsorbent media, ${ }^{167-169}$ biomaterials, ${ }^{170-173}$ and chromatographic materials. ${ }^{174-176}$ Similarly macroporous ceramics can be employed as lightweight thermal and electrical insulators, as well as for catalysis. ${ }^{177-180}$

Colloidal crystals are also of fundamental interest. The statistical mechanics of these complex fluids is a hot topic [see for example "Interactions, structure and phase behaviour of colloidal dispensers," London, 2526 October 2000, The Royal Society]. Once we move beyond the pure hard-sphere systems or the opposite limit of highly charged particles in low salt solutions, there arise many interesting equilibrium statistical 
mechanics questions about what structures will assemble or can be induced to assemble. ${ }^{100,109,181}$ How do real particle interactions, polydispersity, sedimentation, and external forces affect assembly? What is the nature of glassy colloids and colloidal gels, and what are the conditions that induce these structures rather than crystals? What is the nature of the interfaces between liquid/solid and liquid/liquid phases? Answers to some of these questions in model systems will stimulate new thinking about the role of various colloidal mechanisms in affecting protein crystallization-macromolecules in solution which are quite similar in many respects to the systems we are studying.

Besides basic statistical physics, these materials offer the possibility to study fundamental issues about other fields. For example, in quantum optics (or photonics) there have been relatively few experiments testing predictions about the optical properties of direct structures in the case of large dielectric mismatch; such studies are complementary to work done so far on inverse structures. Since we can characterize individual particles relatively easily, measurements in the direct systems may be understood more easily than their inverse counterparts - particularly if defects turn out to have substantive influence. The particle systems also offer a more natural system for controlled introduction of defects and/or unusual background fluids (e.g., liquid crystals, fluorophores, etc.). Other sets of fundamental investigations explore the manifestations of lattice periodicity on transport. For example, how does a polymer (or large macromolecule, cell organelle, cell, etc.) diffuse through an ordered network, what is the role of particle interactions with the diffusing species in these networks, and can these networks be useful as sensitive molecule separators? Or, in a different vein, how would a three-dimensionally ordered array of superconducting material affect the magnetic flux lattices that thread through it or the motion of charge?

Despite many years of practice and innovation, colloidal crystals grown on earth usually have defects. This is due in part to nonideal particle interactions (which leads to a less than perfect knowledge about the phase-diagrams), but more importantly to poorly controlled kinetic processes (which are affected by hydrodynamics, sedimentation, interaction, particle histories, etc.). In special cases, such as the equilibrium assembly of hard-sphere PMMA particles in organic solvent mixtures, good control is achieved, but few other particles can be made to work so perfectly. Similarly, templating on earth has been used with some success to nucleate well-ordered crystals of specific particle types. Nevertheless it is more common that defects arise in practice, including point defects, dislocations, stacking defects, twinning planes; polycrystalline samples are common and many practical limitations arise that are unique to different processing schemes $^{76,77,112,115,182-206}$ - especially when the samples are dried or during solvent exchange, e.g., microcracking, limiting crystal thickness, and local lattice distortions. The detrimental affects of such defects on three-dimensionally ordered colloidal devices are poorly understood. Nevertheless they are expected to be significant. For example, in principle the photonic properties of a colloidal crystal are substantially changed by stacking defects, though their detailed affects are poorly understood. In a similar vein, crystalline disorder within a periodic array of superconducting particles directly affects the Hamiltonian that governs the superconducting wavefunction. While the affects of disorder can be interesting, they must be handled in a statistical way and they will clearly change the physics of the vortices that thread through these materials.

Microgravity offers a qualitatively new environment to improve our control over the equilibrium colloidal assembly process, and thus develop methods to make crystals with fewer defects. In particular, the assembly of colloidal particles in microgravity, using surface templates, pioneers a novel path towards the epitaxial growth of three-dimensional colloidal lattices of unusual particle systems in unusual arrangements.

\section{MEASUREMENTS OF PHOTONIC BANDSTRUCTURE}

Photonic crystals are three-dimensional periodic dielectric structures. In essence all of our crystals will have this property to varying degrees. To be "photonic" the refractive index mismatch between the particles and the background medium need only vary on length scales of order the light wavelength. ${ }^{208,209}$ Measurements of photonic bandstructure provide a useful way to characterize the crystals we make, particularly since microscopy may become limited as the dielectric contrast between particle and background increases. The propagation of light in these materials is similar to the propagation of electrons in conventional crystalline solids. The periodic structure (i.e., the periodic optical potential) gives rise to stop bands at certain frequencies and in certain directions. Under the optimum conditions (e.g., the correct real space structure, and large index mismatches) it is possible that a bandgap for photons can form. In this case, light of certain frequencies cannot freely propagate within the crystal in any spatial direction. There have been many uses proposed for these materials, ${ }^{210-212}$ and substantial photonic bandgap effects have been observed at selected wavelengths (e.g. in the microwave ${ }^{213}$ and far infrared ${ }^{160,214-216}$ region of the spectrum), in 2-dimensions, ${ }^{217-221}$ and in two-dimensional structures 
that use conventional index guiding in the third dimension. $^{222-236}$ There have been a few heroic schemes proposed to make these structures at lower wavelengths, which have also led to some degree of success/demonstration (e.g., ${ }^{106,237,238}$ ).

Nevertheless it is safe to say no general method has yet emerged as a robust solution for the creation of three-dimensional materials with full bandgaps in the visible and NIR part of the electromagnetic spectrum. Furthermore, and perhaps more important for this proposal, there is an enormous amount of science that remains to be done on these materials (with or without full bandgaps). An experimental understanding of the affects of crystal defects on photonic bandstructure is lacking. In fact, detailed measurements of photonic bandstructure have only been reported in relatively few cases, and most of these cases are restricted to direct structures with relatively weak particle scattering and some disorder, ${ }^{151,239-245}$ or to the inverted structures made, for example, by filling the voids in artificial opal with high index material, and then removing the opal, ${ }^{74,75,125,156,246}$ or other variants of this scheme. ${ }^{126,240,247,248}$ To date the inverted materials have demonstrated the most "photonic" behavior (though not a full gap). Thus measurements in many systems (e.g., direct structures with high index particles) are still desirable in order to test our basic understanding of photonics, and open up new ideas for the future.

Several approaches have been used to study photonic bandstructure. ${ }^{136,139,240-242,248-250}$ With few exceptions, ${ }^{251}$ the measurements have been complicated by the fact that the samples were not usually single crystals. These methods range from studies of the spectrum of embedded fluorescent molecules, to studies of transmission versus wavelength at fixed angle, to angle-dependent studies of reflection or transmission versus wavelength. The most powerful studies are the angle-dependent experiments because they allow the experimenter to map out different points in the Brillouin zone. Ultimately this latter technique requires close collaboration with theory, and it also provides a very good test of theoretical models. We will use the angle- and wavelength-dependent reflection measurement in our space experiments.

\section{KEY ISSUES WHERE KNOWLEDGE IS STILL LACKING}

The microgravity environment enables us to ask and answer new questions about colloidal assembly and photonics, and enables us to synthesize novel colloidal materials that cannot be made on earth. The experiments we propose are not precision experiments: we will not measure scaling exponents in a gravity free environment. Instead, our experiments push the boundaries of known self-assembly processes in complex fluids, produce new photonic structures and provide a novel test bed for detailed exploration of some critical questions in photonics. In the process we also lay the groundwork for future colloid engineering in space; major capabilities we address include colloid growth, microscopic and photonic colloid characterization, colloid fixation, and colloid survivability upon return to the earth. The deliverables are three-dimensional micron-scale patterned materials to be investigated directly in space, and further explored on earth.

\section{Colloid Science}

Most of the novel particle systems we aim to assemble are less monodisperse, and less like hardspheres than the PMMA samples we study on earth. Current understanding of the crystallization process in these more complex systems with other significant particle interactions (e.g., screened Coulomb, van der Waals, dipolar, steric, nonsphericity, etc.) derives almost exclusively from what we know about the hard-sphere systems, and is thus incomplete. Clean observations of phase transitions in these more complex systems are needed for insight about the interplay of particle interactions, polydispersity and sedimentation that are normally masked in experiments on earth. Clean observations, for example, about how the liquidous lines are perturbed by particle non-ideality will reveal trends that are broadly useful in complex fluids - trends that should improve design criteria for control of soft materials ranging from protein crystallization to paints.

Our use of templates for "equilibrium" colloidal epitaxy opens up large questions about nucleation and metastability. There are relatively few careful studies of colloidal epitaxy. In microgravity if should be possible to grow open and exotic structures by exploiting epitaxy. Traditional questions about the relative stability of BCC and FCC phases, and the passing from one phase to the other, can be studied in the simplest of systems with exquisite resolution, without the perturbing effects of sedimentation. Both order and disorder can be induced by the surface templates, so that new questions about glass formation can be studied. The nature of nucleation and the configurations of the solid-liquid interface are poorly understood, and the current experiments provide a window into these processes as well.

\section{Photonics}

An enormous amount of science remains to be done with micropatterned photonic materials (with or without full bandgaps). Despite steady progress, there are still relatively few detailed measurements of photonic bandstructure. Most of this work has focused on inverse structures. Considerably less experimental 
work has been carried out on the direct structures wherein the particles themselves are the 'indexmismatching' material, and most of these investigations have employed low-contrast or disordered/imperfect media. We are targeting high-contrast direct structures for our microgravity studies, because their synthesis is much more difficult to accomplish on earth. The direct structure requires much fewer steps to create compared to the inverse structure, and is thus easier to control and characterize. The direct structures provide a critical testing ground for important fundamental questions such as the role of disorder, polycrystallinity, polydispersity, dopants, etc., in affecting photonic bandstructure over a broad range of systems. These measurements will be carried out in-situ, and postmission. Since the particles are generally well characterized, and since we will have some microscopic information about the particle positions, comparison between theory and experiment in the direct structures probably will have fewer uncontrolled parameters than the inverse structures.

Some useful investigations made possible by the entropic assembly processes range from photonic bandstructure measurements of both open and closed crystal structures of the same particles, to measurements of the affects of particle doping. In microgravity, for example, it will be readily possible to mix together different particles that normally segregate in the earth's gravitational field; these more complex mixtures can still be assembled into single crystals. Photonic measurements of these systems as a function of particle doping concentration and as a function of differing particle contrasts will provide useful insight about the modification and destruction of photonic bandstructures. For example, using two particles with the same size but different optical contrast, we can study the transition from a photonic crystal to a more "glassy" photonic material, which have particles at the same spatial positions, but have different overall optical heterogeneity. Detailed microscopic observations of the crystals will facilitate a correlation of structural defects with photonic bandstructure. All of these experiments provide new tests of theory.

In total this project is different from many space experiments because we are not measuring a single phenomenon with enormous precision, and because we anticipate a range of open-ended post-mission studies on earth to further explore novel colloidal crystalline materials that are synthesized in microgravity and returned to earth.

\section{ANTICIPATED KNOWLEDGE TO BE GAINED,} VALUE, AND APPLICATION

This section collates the ideas presented more extensively in earlier sections.
The prospect for creating novel colloidal materials is a primary motivation for the fundamental studies we propose. The experiments pioneer colloid engineering in space. We will derive a definitive set of data about a broad range of particle types and 3D structures that can be readily synthesized entropically without complications of gravity. Entropic crystallization processes are attractive because they do not require extensive amounts of particle-specific solution chemistry. Furthermore our experiments focus on microgravity synthesis in simple solvents (e.g., water), rather than in highly specialized solvents that reduce effects of gravity on earth. We will pioneer fixation of colloidal structures in space, and will determine the survivability of these materials in re-entry. These latter studies are very important, because typically a much broader set of experiments can be performed on the resultant structures once they have been returned to earth.

The experiments push the boundaries of known self-assembly and thermodynamics processes in complex fluids. Clean observations of phase transitions (liquid-solid, liquid-liquid?) in more complex systems consisting of particles whose direct interactions are beyond hard-sphere, provide much needed insight about the interplay of particle interactions, polydispersity and sedimentation in affecting phase behavior. These effects are normally masked in experiments on earth. Clean observations, for example, about how the liquidous lines are perturbed by particle non-ideality reveal trends that are broadly useful in suspension science - trends that should improve design criteria for control of soft materials ranging from protein crystallization to paints. Careful studies of colloidal epitaxy with templates in microgravity will break new ground about the possibilities for growth of closedpacked, open and exotic colloidal structures. Traditional questions about the relative stability of BCC and FCC phases, and the passing from one phase to the other, can be studied in the simplest of systems with exquisite resolution without the perturbing effects of sedimentation. Disorder can also be induced by the surface templates, so that new questions about glass formation can be studied in microgravity. The nature of nucleation and the configurations of the solid-liquid (and solid-solid) interface are poorly understood, and the current experiments provide new windows into these processes.

The experiments will provide new quantitative and qualitative tests of photonics theory. The photonic bandstructures of a wide variety of highly ordered direct particle structures will be determined for the first time. These materials will provide experimental tests of the role of overall crystal structure. More importantly, the experiments will enable us to answer fundamental questions such as the role of disorder, polycrystallinity, 
polydispersity, dopants, etc., in affecting photonic bandstructure over a broad range of systems. The experiments are particularly well suited for studies of particle doping. These studies will also contribute to the establishment of the photonic bandstructure measurement technique as a new method to characterize any highly scattering, ordered dielectric structure.

The products may be of technological importance in the form of novel microelectronic masks, optical filters, switches, photonic bandgap materials for ultralow-noise light-sources, and strong ceramics. The products may also be of basic scientific interest, for example: (1) The structured photon density of states of photonic bandgap crystals provides interesting cavities for studies in quantum optics, and arrays of quantum dots should have novel energy, charge, and exciton transport properties. (2) Ordered three-dimensional arrays of superconductors will provide a unique pinning environment for vortices in magnetic fields enabling fundamental studies of vortex lattices and motions. (3) Entropically driven assembly of metallic, reactive, or magnetic particles in microgravity suspension environments will define new routes for the synthesis of novel materials.

\section{REFERENCES}

1. Dinsmore, A.D., Crocker, J.C., Yodh, A.G., Curr Opin Colloid Interface Sci 3, 5-11 (1998).

2. Underwood, S.M., van Megen, W., Pusey, P.N., Physica A 221, 438-444 (1995).

3. Pusey, P.N., van Megen, W., Physica Scripta 45, 261-164 (1992).

4. Henderson, S.I., van Megen, W, Phys. Rev. Lett. 80, 877-880 (1998).

5. Pusey, P.N., van Megen, W., Nature 320, 340-342 (1986).

6. Russel, W.B., Chaikin, P.M., Zhu, J., Meyer, W.V., Rogers, R., Langmuir 13, 3871-388 (1997).

7. Zhu, J.X., Li, M., Rogers, R., Meyer, W., Ottewill, R.H., Russell, W.B., Chaikin, P.M., Nature 387, 883-885 (1997).

8. Phan, S.E., Russel, W.B., Cheng, Z.D., Zhu, J.X., Chaikin, P.M., Dunsmuir, J.H., Ottewill, R.H., Phys Rev E 54, 6633-6645 (1996).

9. Rutgers, M.A., Dunsmuir, J.H., Xue, J.Z., Russel, W.B., Chaikin, P.M., Phys Rev B 53, 5043-5046 (1996).

10. Henderson, S.I., Mortensen, T.C., Underwood, S.M., van Megen, W., Physica A 233, 102-116 (1996).

11. Piazza, R., Bellini, T., DeGiorgio, V., Phys Rev Lett 71, 4267-4270 (1993).
12. Bolhuis, P.G., Frenkel, D., Mau, S.C., Huse, D.A., Nature 388, 235-236 (1997).

13. Crocker, J.C., Matteo, J.A., Dinsmore, A.D., Yodh, A.G., Physical Review Letters 82, 4352-4355 (1999).

14. Verma, R., Crocker, J.C., Lubensky, T.C., Yodh, A.G., Physical Review Letters 81, 4004-4007 (1998).

15. Dinsmore, A.D., Yodh, A.G., Pine, D.J., Nature 383, 239-242 (1996).

16. Dinsmore, A.D., Wong, D.T., Nelson, P., Yodh, A.G., Phys Rev Lett 80, 409-412 (1998).

17. Dinsmore, A.D., Warren, P.B., Poon, W.C.K., Yodh, A.G., Europhys Lett 40, 337-342 (1997).

18. Dinsmore, A.D., Yodh, A.G., Pine, D.J., Phys . Rev. E. 52, 4045-4057 (1995).

19. Kaplan, P.D., Rouke, J.L., Yodh, A.G., Pine, D.J., Phys. Rev. Lett. 72, 582-585 (1994).

20. Kaplan, P.D., Yodh, A.G., Pine, D.J., Physical Review Letters 68, 393-396 (1992).

21. Dickman, R., Attard, P., Simonian, V., J Chem Phys. 107, 205-213 (1997).

22. Eldridge, M.D., Madden, P.A., Pusey, P.N., Bartlett, P., Mol Phys 84, 395-420 (1995).

23. Poon, W.C.K., Warren, P.B., Europhys Lett. 28, 513-518 (1994).

24. Poon, W.C.K, Pirie, A.D., Haw, M.D., Pusey, P.N., Physica A 235, 110-119 (1997).

25. Poon, W.C.K., Pirie, A.D., Pusey, P.N., Faraday Discuss 101, 65-76 (1995).

26. Poon, W.C.K., Ilett, S.M., Pusey, P.N., Nuovo Cimento D 16, 1127-1139 (1994).

27. Poon, W.C.K., Pirie, A.D., Haw, M.D., Pusey, P.N., Physica A 235, 110-119 (1997).

28. Warren, P.B., Ilett, S.M., Poon, W.C.K., Phys Rev E 52, 5205-5213 (1995).

29. Bartlett, P., Pusey, P.N., Physica A 194, 415-423 (1993).

30. Lekkerkerker, H.N.W., Poon, W.C.K., Pusey, P.N., Stroobants, A., Warren, P.B., Europhys Lett 20, 559-564 (1992).

31. Biben, T., Hansen, J.P., Physica A 235, 142-148 (1997).

32. Dijkstra, M., Frenkel, D., Hansen, J.P., J Chem Phys 101, 3179-3189 (1994).

33. Biben, T., Hansen, J.P., Mol Phys 80, 853-859 (1993).

34. Biben, T., Hansen, J.P., Phys Rev Lett 66, 2215-2218 (1991).

35. Imhof, A., Dhont, J.K.G., Colloid Surface A 122, 53-61 (1997).

36. Imhof, A., Dhont, J.K.G., Phys Rev Lett 75, 1662-1665 (1995). 
37. Meller, A., Stavans, J., Langmuir 12, 301-304 (1996).

38. Steiner, U., Meller, A., Stavans, J., Phys Rev Lett 74, 4750-4753 (1995).

39. Mondainmonval, O., Lealcalderon, F., Phillip, J., Bibette, J., Phys Rev Lett 75, 3364-3367 (1995).

40. Calderon, F.L., Bibette, J., Biais, J., Europhys Lett 23, 653-659 (1993).

41. Bibette, J., Roux, D., Pouligny, B., J Phys II 2, 401-424 (1992).

42. Bibette, J., J Colloid Interf Sci 147, 474-478 (1991).

43. Bibette, J., Roux, D., Nallet, F., Phys Rev Lett 65, 2470-2473 (1990).

44. Bartlett, P., Ottewill, R.H., Langmuir 8, 1919-1925 (1992).

45. Bartlett, P., Ottewill, R.H., Pusey, P.N., Phys Rev Lett 68, 3801-3804 (1992).

46. Sear, R.P., Frenkel, D., Phys Rev E 55, 1677-1681 (1997).

47. Biben, T., Bladon, P., Frenkel, D., J PhysCondens Mat 8, 10799-10821 (1996).

48. Bodnar, I., Dhont, J.K.G., Lekkerkerker, H.N.W., J Phys Chem-US 100, 19614-19619 (1996).

49. Verhaegh, N.A.M., van Duijneveldt, J.S., Dhont, J.K.G., Lekkerkerker, H.N.W., Physica A 230, 409--436 (1996).

50. Mao, Y., Cates, M.E., Lekkerkerker, H.N.W., Physica A 222, 10-24 (1995).

51. Ilett, S.M., Orrock, A., Poon, W.C.K., and Pusey, P.N., Phys. Rev. E. 51, 1344-1352 (1995).

52. De Hek, H., Vrij, A., J. Colloid Interface Sci. 84, 409 (1981).

53. Adams, M., Dogic, Z., Keller, S.L., Fraden, S., Nature 393, 349-352 (1998).

54. Adams, M., Fraden, S., Biophys J 74, 669-677 (1998).

55. Dogic, Z., Fraden, S., Phys Rev Lett 78, $2417-$ 2420 (1997).

56. Tang, J.X., Franden, S., Liquid Cryst 19, 459-467 (1995).

57. Mao, Y., Bladon, P., Lekkerkerker, H.N.W., Cates, M.E., Mol Phys 92, 151-159 (1997).

58. Bolhuis, P.G., Stroobants, A., Frenkel, D., Lekkerkerker, H.N.W., J Chem Phys 107, 1551-1564 (1997).

59. van Bruggen, M.P.B., vander Kooij, F.M., Lekkerkerker, H.N.WJ Phys-Condens Mat 8, 9451-9456 (1996).

60. Polson, J.M., Frenkel, D., Phys Rev E 56, R6260-R6263 (1997).

61. Poulin, P., Weitz, D.A., Phys Rev E 57, 626-637 (1998).
62. Poulin, P., Stark, H., Lubensky, T.C., Weitz, D.A., Science 275, 1770-1773 (1997).

63. Lubensky, T.C., Pettey, D., Currier, N., Stark, H., Phys Rev E 57, 610-625 (1998).

64. Larsen, A.E., Grier, D.G., Nature 385, 230-233 (1997).

65. Crocker, J.C., Grier, D.G., Phys Rev Lett 77, 1897-1900 (1996).

66. Larsen, A.E., Grier, D.G., Phys Rev Lett 76, 3862-3865 (1996).

67. Reus, V., Belloni, L., Zemb, T., Lutterbach, N., Versmold, H., J Phys II 7, 603-626 (1997).

68. Murray, C.A., Colloids: Nature 385, 203-204 (1997).

69. van Roij, R., Hansen, J.P., Phys Rev Lett 79, 3082-3085 (1997).

70. Tata, B.V.R., Yamahara, E., Rajamani, P.V., Ise, N., Phys Rev Lett 78, 2660-2663 (1997).

71. Tata, B.V.R., Arora, A.K., Phys Rev Lett 75, 3200 (1995).

72. Xia, Y.N., Gates, B, Yin, Y.D., Lu, Y., Advanced Materials 12, 693-713 (2000).

73. Imhof, A., Pine, D.J., Nature 389, 948-951 (1997).

74. Holland, B.T., Blanford, C.F., Stein, A., Science 281, 538-540 (1998).

75. Wijnhoven, J.E.G.J., Vos, W.L., Science 281, 802-804 (1998).

76. Hulteen, J.C., Van Duyne, R.P., Journal of Vacuum Science \& Technology A 13, 1553-1558 (1995).

77. Winzer, M., Kleiber, M., Dix, N., Wiesendanger, R., Appl Phys A-Mater 63, 617-619 (1996).

78. Storhoff, J.J., Elghanian, R., Mucic, R.C., Letsinger, R.L., Mirkin, C.A., J Am Chem Soc 120, 1959-1964 (1998).

79. Elghanian, R., Storhoff, J.J., Mucic, R.C., Letsinger, R.L., Mirkin, C.A., Science 277, 1078-1081 (1997).

80. Minton, A.P., Method Enzymol 295, 127-149 (1998).

81. Minton, A.P., Biophys Chem 57, 1-2 (1995).

82. Asakura, S., Oosawa, F., J. Chem. Phys. 22, 1255 (1954).

83. Vrij, A., Pure and Applied Chem. 48, 471-483 (1976).

84. Gast, A.P., Hall, C.K., Russel, W.B., J. Colloid and Interface Sci. 96, 251 (1983).

85. Verma, R., Crocker, J.C., Lubensky, T.C., and Yodh, A.G., Macromolecules 33, 177-186 (2000).

86. Yodh, A.G., Lin, K-H., Crocker, J.C., Dinsmore, A.D., Verma, R., and Kaplan, P.D., The 
Philosophical Transactions of the Royal Society of London A 359, 921-937 (2001).

87. Sanyal, S., Easwar, N., Ramaswamy, S., Sood, A.K., Europhys. Lett. 18, 107-110 (1992).

88. van Duijneveldt, J.S., Heinen, A.W., Lekkerkerker, H.N.W., Europhys. Lett. 21, 369-374 (1993).

89. Rosenfeld, Y., Phys. Rev. Lett. 72, 3831-3834 (1994).

90. Carnahan, N.F, and Starling, K.E., J. Chem. Phys. 51, 635 (1969).

91. Bartlett, P., Ottewill, R.H., Pusey, P.N. J. Chem. Phys. 93, 1299-1312 (1990).

92. Sanders, J.V., Philosophical Mag A 42, 705-720 (1980).

93. Denton, A.R., Ashcroft, N.W., Phys Rev A 42, 7312-7329 (1990).

94. Eldridge, M.D., Madden, P.A., Frenkel, D., Mol Phys 79, 105-120 (1993).

95. Bartlett, P., J Phys Condens Matter 2, 4979-4989 (1990).

96. Bartlett, P., Journal of Physics-Condensed Matter 12, A275-A280 (2000).

97. Warren, P.B., Physical Review Letters 80, 1369-1372 (1998).

98. Evans, R.M.L., Fairhurst, D.J., Poon, W.C.K., Physical Review Letters 81, 1326-1329 (1998).

99. Dinsmore, A.D., Yodh, A.G., Langmuir 15, 314-316 (1999).

100. Lin, K-H, Crocker, J.C., Prasad, V., Schofield, A., Weitz, D.A., Lubensky, T.C., and Yodh, A.G., Physical Review Letters 85, 1770-1773 (2000).

101. Chou, S.Y., Krauss, P.R., Zhang, W., Guo, L.J., and Zhuang, LJ. Vac. Sci. Technol. B 15, 2897-2904 (1997).

102. Xia, Y., Kim, E., Zhao, X-M., Rogers, J.A., Prentiss, M., Whitesides, G.M., Science 273, 347-349 (1996).

103. Antl, L., Goodwin, J.W., Hill, R.D., Ottewill, R.H., Owens, S.M., Papworth, S., Waters, J.A., Colloids and Surfaces 17, 67-78 (1986).

104. Cheng, C.C., Scherer, A., Arbet-Engels, V., Yablonovitch, E., J Vac Sci Technol B 14, 4110 (1996).

105. Foresi, J.S., Villeneuve, P.R., Ferrera, J., Thoen, E.R., Steinmeyer, G., Fan, S., Joannopoulos, J.D., Kimerling, L.C., Smith, H.I., Ippen, E.P., Nature 390, 143 (1997).

106. Lin, S.Y., Fleming, J.G., Hetherington, D.L., Smith, B.K., Biswas, R., Ho, K.M., Sigalas, M.M., Zubrzycki, W., Kurtz, S.R., Bur, J., Nature 394, 251 (1998).
107. Campbell, M., Sharp, D.N., Harrison, M.T., Denning, R.G., Turberfield, A.J., Nature 404, 53 (2000).

108. Gast, A.P., Russel, W.B., Physics Today, 51, 24-30 (1998).

109. Ackerson, B.J., Pusey, P.N., Phys. Rev. Lett. 61 1033-1036 (1988).

110. van Blaaderen, A., Ruel, R., Wiltzius, P., Nature 385, 321-324 (1997).

111. Micheletto, R., Fukuda, H., Ohtsu, M., Langmuir 11, 3333 (1995).

112. Denkov, N.D., et al., Nature 361, 26 (1993).

113. Peterson, I., Science News 148, 296 (1995).

114. Kralchevsky, P.A., Nagayama, K., Langmuir 10, 23-36 (1994).

115. Jiang, P., Bertone, J.F., Hwong, K.S., Colvin, V.L., Chemistry of Materials 11, 2132-2140 (1999).

116. Jiang, P., Hwang, K.S., Mittleman, D.M., Bertone, J.F., Colvin, V.L., J Am Chem Soc 121, 11630-11637 (1999).

117. Holgado, M., Garcia-Santamaria, F., Blanco, A., Ibisate, M., Cintas, A., Miguez, H., Serna, C.J., Molpeceres, C., Requena, J., Mifsud, A., Meseguer, F., Lopez, C., Langmuir 15, 4701-4704 (1999).

118. Trau, M., Saville, D.A., Aksay, I.A., Science 272, 706-709 (1996).

119. Yeh, S.R., Seul, M., Shraiman, B.I., Nature 386, 57-59 (1997).

120. Aizenberg, J., Braun, P.V., Wiltzius, P., Physical Review Letters 84, 2997-3000 (2000).

121. Qin, D., Xia, Y.N., Xu, B., Yang, H., Zhu, C., Whitesides, G.M., Advanced Materials 11, 1433-1437 (1999).

122. Park, S.H., Qin, D., Xia, Y., 10, 1028 (1998).

123. Gates, B., Qin, D., Xia, Y.N., Advanced Materials 11, 466 (1999).

124. Velev, O.D., Tessier, P.M., Lenhoff, A.M., Kaler, E.W., Nature 401, 548 (1999).

125. Vlasov, A.Y., Yao, N., Norris, D.J., Adv Mater 11, 165 (1999).

126. Subramania, G., Constant, K., Biswas, R., Sigalas, M.M., Ho, K.M., Appl Phys Lett 74, 3933-3935 (1999).

127. Yablonovitch, E., Nature 401, 539 (1999).

128. Pan, G., Kesavamoorthy, R., Asher, S.A., Phys Rev Lett 78, 3860-3863 (1997).

129. Lin S.Y., Chow, E., Hietala, V., Villeneuve, P.R., Joannopoulos, J.D., Science 282, 274-276 (1998).

130. Gupta, S., Tuttle, G., Sigalas, M., Ho, K.M., Appl Phys Lett 71, 2412-2414 (1997).

131. Bullock, D.L., Shih, C.-C., Margulies, R.S., J Opt Soc Am B 10, 399-403 (1993). 
132. Lei, X., Li, H., Ding, F., Zhang, W., Ming, N., Appl Phys Lett 71, 2889-2891 (1997).

133. Flaugh, P.L., O'Donnell, S.E., Asher, S.A., Appl Spectrosc 38, 847-850 (1984).

134. Herbert, C., Malcuit, MOpt Lett 18, 1783-1785 (1993).

135. Megens, M., Wijnhoven, J.E.G.J., Lagenkijk, A., Vos, W.L., J Opt Soc Am B, 16, 1403 (1999).

136. Megens, M., Wijnhoven, J.E.G.J., Lagenkijk, A., Vos, W.L., Phys Rev Lett A 59, 4727 (1999).

137. Dowling, J.P., Scalora, M., Bloemer, M.J., Bowden, C.M., J Appl Phys 75, 1896-1899 (1994).

138. Hirayama, H., Hamano, T., Aoyagi, Y., Appl Phys Lett 69, 791-793 (1996).

139. Petrov, E.P., Bogomolov, V.N., Kalosha, I.I., Gaponenko, S.V., Phys Rev Lett 81, 77-80 (1998).

140. Martorell, J., Lawandy, N.M., Phys Rev Lett 66, 887-890 (1991).

141. Vlasov, Y.A., Luterova, K., Pelant, I., Honerlage, B., Astratov, V.N., Appl Phys Lett 71, 1616-1618 (1997).

142. Asher, S.A., Holtz, J., Weissman, J., Pan, G., MRS Bull 23, 44-50 (1998).

143. Carlson, R.J., and Asher, S.A., Appl Spectrosc 38, 297-304 (1984).

144. Rundquist, P.A., Photinos, P., Jagannathan, S., Asher, S.A., J Chem Phys 91, 4932-4941 (1989).

145. Asher, S.A., Holtz, J., Liu, L., Wu, Z., J Am Chem Soc 116, 4997-4998 (1994).

146. Asher, S.A., Jagannathan, S., US Patent 5,281,370 (1994).

147. Asher, S.A., Chang, S-Y, Tse, A., Liu, L., Pan, G., Wu, Z., Li, P., in Materials for Optical Limiting, edited by Crane, R., Lewis, K., Van Stryland, E., Khoshnevisan, M., (Mater. Res. Soc. Symp. Roc. 374, Pittsburgh, 1995), p. 305.

148. Chang, S-Y., Liu, L., Asher, S.A., in Better Ceramics Through Chemistry VI, edited by Cheetham, A.K., Brinker, C.J., Mecartney, M.L., Sanchez, C., (Mater. Res. Soc. Symp. Proc. 346, Pittsburgh, 1994), p. 875.

149. Spry, R.J., and Kosan, D.J., Appl Spectrosc 40, 782-784 (1986).

150. Weissman, J., Sunkara, H.B., Tse, A.S., Asher, S.A., Science 274, 959-960 (1996).

151. Holtz, J.H., Asher, S.A., Nature 389, 829-832 (1997).

152. Sigalas, M.M., Soukoulis, C.M., Biswas, R., Ho, K.M., Phys Rev B 56, 959-962 (1997).

153. Lidorikis, E., Li, Q., Soukoulis, C.M., Phys Rev Lett 55, 3613-3616 (1997).
154. Lidorikis, E., Li, Q., Soukoulis, C.M., Phys Rev B 53, 10249-10252 (1996).

155. Li, Q., Chan, C.T., Ho, K.M., Soukoulis, C.M., Phys Rev B 53, 15577-15585 (1996).

156. Zakhidov, A.A., Baughman, R.H., Iqbal, Z., Cui, C., Khayyrullin, I., Dantas, O., Marti, J., Ralchenko, V.G., Science 282, 897-901 (1998).

157. Biswas, R., Sigalas, M.M., Subramania, G., Soukoulis, C.M., Ho, K.M., Phys Rev B 61, 4549-4553 (2000).

158. Imhof, A., Pine, D.J., Nature 389, 448 (1997).

159. Velev, A., Jede, T.A., Lobo, R.F., Lenhoff, A.M., Nature 389, 447-448 (1997).

160. Sozuer, H.S., Haus, J.W., Inguva, R., Phys Rev B 45, 13962-13972 (1992).

161. Suzuki, T., Yu, P.K.L., Opt Soc Am B 12, 570-582 (1995).

162. Biswas, R., Sigalas, M., Subramania, G., Ho, K.M., Phys Rev B 57, 3701-3705 (1998).

163. Busch, K., John, S., Phys Rev E 58, 3896-3908 (1998).

164. Biswas, R., Sigalas, M., Soukoulis, C.M., Ho, K.M., in Photonic Band Gap Materials, vol. 315 of NATO Advanced Study Institute Series E: Applied Sciences, edited by Soukoulis, C.M., (Kluwer, Dordrecht, 1996).

165. Tanev, P.T., Chibwe, M., Pinnavaia, T.J., Nature 368, 321-323 (1994).

166. Deleuze, H., Schultze, X., Sherrington, D.C., Polymer 39, 6109-6114 (1998).

167. Bhave, R.R., Inorganic Membranes: Synthesis, Characteristics and Applications; Van Nostrand Reinhold: New York, 1991.

168. Lewandowski, K., Murer, P., Svec, F., Frechet, J.M.J., Anal Chem 70, 1629-1638 (1998).

169. Akolekar, D.B., Hind, A.R., Bhargava, S.K., J Colloid Interface Sci 199, 92-98 (1998).

170. Maquet, V., Jerome, R., Mater Sci Forum 250, 15-42 (1997).

171. Peters, M.C., Mooney, D.J., Mater Sci Forum 250, 43-52 (1997).

172. Bancel, S, Hu, W.S., Biotechnol Prog 12, 398402 (1996).

173. Schugens, C., Maquet, V., Grandfils, C., Jerome, R., Teyssie, P., Polymer 37, 1027-1038 (1996).

174. Tennikov, M.B., Gazdina, N.V., Tennikova, T.B., Svec, F., J Chromatogr A 798, 55-64 (1998).

175. Palm, A., Novotny, M.V., Anal Chem 69, 4499-4507 (1997).

176. Xie, S.F., Svec, F., Frechet, J.M.J., J Chromatogr A 775, 65-72 (1997).

177. Litovsky, E., Shapiro, M., Shavit, A., J Am Ceram Soc 79, 1366-1376 (1996). 
178. Seino, H., Haba, O., Mochizuki, A., Yoshioka, M., Ueda, M., High Perform Polym 9, 333-344 (1997).

179. Senkevich, J.J., Desu, S.B., Appl Phys Lett 72, 258-260 (1998).

180. Sedev, R., Ivanova, R., Kolarov, T., Exerowa, D., J Dispersion Sci Technol 18, 751-767 (1997).

181. Russel, W.B., Saville, D.A., Schowalter, W.R., Colloidal Dispersions. New York: Cambridge University Press, 1989.

182. Miguez, H., Meseguer, F., Lopez, C., Blanco, A., Moya, J.S., Requena, J., Mifsud, A, Fornes, V., Adv Mater 10, 480 (1998).

183. Pieranski, P., Colloidal crystals. Contemp Phys 24, 25-73 (1983).

184. Davis, K.E., Russel, W.B., Glantschnig, W.J., J Chem Soc Faraday Trans 87, 411-424 (1991).

185. Mayoral, R., Requena, J., Moya, J.S., Lopez, C., Cantas, A., Miguez, H., Meseguer, F., Vazquez, L., Holgado, M., Blanco, A., Adv Mater 9, 257 (1997).

186. Jethmalani, J.M., Ford, W.T., Chem Mater 8, 2138-2146 (1996).

187. Jethmalani, J.M., Zunkara, H.B., Ford, W.T., Willoughby, S.L., Ackerson, B.J., Langmuir 13, 2633-2639 (1997).

188. Jethmalani, J.M., Ford, W.T., Beaucage, G., Langmuir 13, 3338-3344 (1997).

189. Clark, N.A., Hurd, A.J., Ackerson, B.J., Nature 281, 57-60 (1979).

190. Okubo, T., Langmuir 10, 1695-1702 (1994).

191. Deckman, H.W., Dunsmuir, J.H., Appl Phys Lett 41, 377-379 (1982).

192. Burmeister, F., Schafle, C., Keilhofer, B., Bechinger, C., Boneberg, J., Leiderer, P., Adv Mater 10, 495-497 (1998).

193. Deckman, H.W., Dunsmuir, J.H., J Vac Sci Technol B 1, 1109-1112 (1983).

194. O'hara, P.C., Leff, D.V., Heath, J.R., Gelbart, W.M., Phys Rev Lett 75, 3466-3469 (1995).

195. Park, S.H., Xia, Y., Adv Mater 10, 1045 (1998).

196. Park, S.H., Xia, Y., Chem Mater 10, 1745 (1998).

197. Park, S.H., Qin, D., Xia, Y., Adv Mater 10, 1028 (1998).

198. Park, S.H., Xia, Y., Langmuir 15, 266-273 (1999).

199. Dimitrov, A.S., Nagayama, K., Langmuir 12, 1303-1311 (1996).

200. Nagayama, K., Phase Transitions 45, 185-203 (1993).

201. Dimitrov, A.S., Dushkin, C.D., Yoshimura, H., Nagayama, K., Langmuir 10, 432-440 (1994).

202. Adachi, E., Dimitrov, A.S., Nagayama, K., Langmuir 11, 1057-1060 (1995).
203. Nagayama, K., Colloids Surf A 109, 363-374 (1996).

204. Dimitrov, A.S., Nagayama, K., Chem Phys Lett 243, 462-468 (1995).

205. Denkov, N.D., Velev, O.D., Kralchevsky, P.A., Ivanov, I.B., Yoshimura, H., Nagayama, K., Langmuir 8, 3183-3190 (1992).

206. Yamaki, M., Higo, J., Nagayama, K., Langmuir 11, 2975-2978 (1995).

207. See [6] and private communication.

208. Yablonovitch, E., Phys Rev Lett 58, 2059-2062 (1987).

209. John, S., Phys Rev Lett 58, 2486-2489 (1987).

210. Photonic band gap materials, edited by C.M. Soukoulis, NATO ASI Vol. E: 315 (Kluwer, Dordrecht, 1996).

211. Yamamoto, Y., Slusher, R.E., Phys Today 46, 66-73 (1993).

212. Joannopoulos, J.D., Villeneuve, P.R., Fan, S.H., Nature 386, 143-149 (1997).

213. Yablonovitch, E., Phys Rev Lett 63, 1950-1953 (1989).

214. Sanders, J.V., Nature 204, 1151-1153 (1964).

215. van Blaaderen, A., Vrij, A., Langmuir 8, 2921-2931 (1992).

216. Meade, R.D., Brommer, K.D., Rappe, A.M., Joannopoulos, J.D., Phys Rev B 44, 10961 (1991a).

217. Yamamoto, N., and Noda, S., Jpn. J. Appl. Phys. 38, 1282-1285 (1999).

218. Plihal, M., Maradudin, A.A., Phys Rev B 44, 8565 (1991).

219. Robertson, W.M., Arjavalingam, G., Meade, R.D., Brommer, K.D., Rappe, A.M., Joannopoulos, J.D., 1993. Phys Rev Lett 69, 2023 (1993).

220. Joannopoulos, J.D., Optics Letters 18, 528 (1993).

221. Villeneuve, P., Piche, M., 1992. Phys Rev B 46, 4969 (1992).

222. Tarhan, I.I., Watson, G.H., Phys Rev Lett 76, 315-318 (1996).

223. Fan, S., Villeneuve, P.R., Joannopoulos, J.D., and Schubert, E.F., Physical Review Letters 78, 3294-3297 (1997).

224. Johnson, S.G., Fan, S., Villeneuve, P.R., Joannopoulos, J.D., and Kolodzieski, L.A., Physical Review B 60, 5751-5758 (1999).

225. Krauss, T., De La Rue, R., and Band, S., Nature 383, 699-702 (1996).

226. Benistry, H., Labilloy, D., Weisbuch, C., Smith, C.J.M., Krauss, T.F., Cassagne, D., Beraud, A., and Jouanin, C., Applied Physics Letters 76, 531-533 (2000). 
227. Villeneuve, P.R., Fan, S., Johnson, S.G., and Joannopoulos, J.D., IEEE Proceedings: Optoelectronics 145, 384 (1998).

228. Boroditsky, M., Vrijen, R., Krauss, T.F., Coccioli, R., Bhat, R., and Yablonovitch, E., J. Lightwave Technology 17, 2096-2112 (1999).

229. Johnson, S.G., Villeneuve, P.R., Fan, S., and Joannopoulos, J.D., Physical Review B 62, 8212-8222 (2000).

230. Kuchinsky, S., Allan, D.C., Borrelli, F., and Cottervert, J.-C., Optics Communication 175, 147 (2000).

231. Chutinan, A., and Noda, S., Physical Review B 62, 4488-4492 (2000).

232. Coccioli, R., Boroditsky, M., Kim, K.W., Rahmat-Samii, Y., Yablonovitch, E., IEEE Proceedings Optoelectronics 145, 391-197 (1998).

233. Painter, O., Vuckovic, T., and Scherer, A., Journal of the Optical Society of America B-Optical Physics 16, 275-285 (1999).

234. Painter, O., Lee, R.K., Scherer, A., Yariv, A., O'Brien, J.D., Dapkus, P.D., and Kim, I., Science 284, 1819-1821 (1999).

235. Baba, T., Fukaya, N., and Yonekura, J., Electronic Letters 35, 654-655 (1999).

236. Lin, S.Y., Chow, E., Johnson, S.G., and Joannopoulos, J.D., Optics Letters. 25, 12971299 (2000).

237. Blanco, A., Chomski, E., Grabtchak, S., Ibisate, M., John, S., Leonard, S.W., Lopez, C., Meseguer, F., Miguez, H., Mondla, J.P., Ozin, G.A., Toader, O., and van Driel, H.M., Nature 405, 437-440 (2000).
238. Noda, S., Tomoda, K., Yamamoto, N., Chutinan, A., Science 289, 604-606 (2000).

239. Pradhan, R.D., Bloodgood, J.A., Watson, G.H., Phys Rev B 55, 9503-9507 (1997).

240. Pradhan, R.D., Tarhan, I.I., Watson, G.H., Phys Rev B 54, 1-6 (1996).

241. Bertone, J.F., Jiang, P., Hwang, K.S., Mittleman, D.M., Colvin, V.L., Phys Rev Lett 83, 300 (1999).

242. Imhof, A., Vos, W.L., Sprik, R., Lagendijk, Ad, Physical Review Letters 83, 2942-2945 (1999).

243. Thijssen, M.S., Sprik, R., Wijnhoven, J.E.G.J.k Megens, et al., Physical Review Letters 83, 2730-2733 (1999).

244. Gates, B., Park, S.H., Xia, Y.N., Advanced Materials 12, 653 (2000).

245. Park, S.H., Gates, B., Xia, Y.N., Advanced Materials 11, 462 (1999).

246. Romanov, S.G., Johnson, N.P., Fokin, A.V., Butko, V.Y., Yates, H.M., Pemble, M.E., Torres, C.M.S., Appl Phys Lett 70, 2091-2093 (1997).

247. Subramania, G., Constant, K., Biswas, R., Sigalas, M.M., Ho, K.M., J Lightwave Technol 17, 1970 (1999).

248. Braun, P.V., Wiltzius, P., Nature 402, 603-604 (1999).

249. Miguez, H., Blanco, A., Meseguer, F., Lopez, C., Yates, H.M., Pemble, M.E., Fornes, V., Mifsud, A., Phys Rev B 59, 1563-1566 (1999).

250. Yoshino, K., Lee, S.B., Tatsuhara, S., Kawagishi, Y., Ozaki, M., Zakhidov, A.A., Appl Phys Lett 73, 3506-3508 (1998).

251. Yu, A., Vlasov, N., Deutsch, M., Norris, D.J., Applied Phys Lett (1999). 
Public reporting burden for this collection of information is estimated to average 1 hour per response, including the time for reviewing instructions, searching existing data sources, gathering and maintaining the data needed, and completing and reviewing the collection of information. Send comments regarding this burden estimate or any other aspect of this collection of information, including suggestions for reducing this burden, to Washington Headquarters Services, Directorate for Information Operations and Reports, 1215 Jefferson Davis Highway, Suite 1204, Arlington, VA 22202-4302, and to the Office of Management and Budget, Paperwork Reduction Project (0704-0188), Washington, DC 20503.

\begin{tabular}{|l|l|l}
\hline 1. AGENCY USE ONLY (Leave blank) & $\begin{array}{c}\text { 2. REPORT DATE } \\
\text { January } 2002\end{array}$ & $\begin{array}{r}\text { 3. REPORT TYPE AND DATES COVERED } \\
\text { Technical Memorandum }\end{array}$ \\
\hline
\end{tabular}

4. TITLE AND SUBTITLE

5. FUNDING NUMBERS

Entropically Driven Self-Assembly of Colloidal Crystals on Templates in Space

6. AUTHOR(S)

Arjun G. Yodh and Gregory A. Zimmerli

WU-398-25-0H-00

7. PERFORMING ORGANIZATION NAME(S) AND ADDRESS(ES)

National Aeronautics and Space Administration

John H. Glenn Research Center at Lewis Field

Cleveland, Ohio 44135-3191

8. PERFORMING ORGANIZATION

REPORT NUMBER

E-13090

9. SPONSORING/MONITORING AGENCY NAME(S) AND ADDRESS(ES)

National Aeronautics and Space Administration

Washington, DC 20546-0001

10. SPONSORING/MONITORING

AGENCY REPORT NUMBER

NASA TM-2002-211287

AIAA-2001-4960

\section{SUPPLEMENTARY NOTES}

Prepared for the International Space Station Utilization-2001 sponsored by the American Institute of Aeronautics and Astronautics, Cape Canaveral, Florida, October 15-18, 2001. Arjun G. Yodh, University of Pennsylvania, Philadelphia, Pennsylvania, and Gregory A. Zimmerli, NASA Glenn Research Center. Responsible person, Gregory A. Zimmerli, organization code 6712, 216-433-6577.

12a. DISTRIBUTION/AVAILABILITY STATEMENT

12b. DISTRIBUTION CODE

Unclassified - Unlimited

Subject Categories: 49 and 60

Distribution: Nonstandard

Available electronically at http://gltrs.grc.nasa.gov/GLTRS

This publication is available from the NASA Center for AeroSpace Information, 301-621-0390.

13. ABSTRACT (Maximum 200 words)

These experiments aim to create new colloidal crystalline materials, to study the assembly and thermodynamics of these materials, to measure the optical properties of these materials, and to fix the resulting structures so that they can be brought back and studied on earth. In microgravity, the elimination of particle sedimentation effects creates a purely "thermodynamic" environment for colloidal suspensions wherein particle size, volume fraction, and interparticle interactions are the primary determinants of the assembled structures. We will control the colloidal assembly process using attractive, entropic particle interactions brought about by the depletion effect. By using attractive interactions for colloidal assembly we create conditions for growth that resemble those associated with "conventional" microscopic systems such as atoms and molecules. This approach differs qualitatively from the more common "space-filling" mode of colloidal crystal growth that is driven purely by packing constraints. It is anticipated that at least some of the solidified structures will survive re-entry to earth's gravitational field, and that their optical, magnetic, and electrical properties can then be studied in detail upon return.

14. SUBJECT TERMS

\begin{tabular}{|l|l|} 
& $\begin{array}{c}15 . \text { NUMBER OF PAGES } \\
22\end{array}$ \\
\cline { 2 - 2 } & 16. PRICE CODE \\
\hline $\begin{array}{l}\text { 19. SECURITY CLASSIFICATION } \\
\text { OF ABSTRACT } \\
\text { Unclassified }\end{array}$ & 20. LIMITATION OF ABSTRACT \\
\hline
\end{tabular}

Colloids; Entropy; Self-assembly; Crystals

Standard Form 298 (Rev. 2-89)

NSN 7540-01-280-5500 